\title{
Erratum to: Neonatal brain MRI: how reliable is the radiologist's eye?
}

\author{
B. Morel ${ }^{1,2}$ - G. Antoni ${ }^{3}$ - J. P. Teglas ${ }^{3}$ - I. Bloch ${ }^{2}$ - C. Adamsbaum ${ }^{2,4}$
}

Published online: 16 November 2015

(C) Springer-Verlag Berlin Heidelberg 2015

\section{Erratum to: Neuroradiology}

DOI: 10.1007/s00234-015-1609-2

Professor Catherine Adamsbaum adds the institutional affiliation: ${ }^{2}$ LTCI, CNRS, Télécom ParisTech, Université Paris-Saclay, Paris, France

The online version of the original article can be found at http://dx.doi.org/ 10.1007/s00234-015-1609-2.

B. Morel
baptistemorelaphp@gmail.com

1 Pediatric Radiology, A. Trousseau Hospital APHP, 26 avenue du Dr Arnold Netter, 75012 Paris, France

2 LTCI, CNRS, Télécom ParisTech, Université Paris-Saclay, Paris, France

3 INSERM, CESP Centre for Research in Epidemiology and Population Health, U1018, Reproduction and Child Development, F-94807 Villejuif, France

4 Pediatric Radiology Department Bicêtre Hospital APHP, Faculty of Medicine, Paris Sud University, Paris, France 